

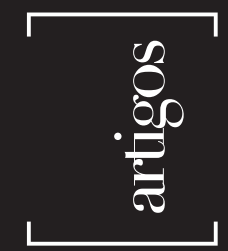


artigo $]$

\title{
A moda refletida no espelho da MPB
}

\section{Fashion reflects in brazilian popular music mirror}

\author{
[ FRED GÓES ] \\ É carioca, prof. doutor da Faculdade de Letras \\ da UFRJ, pós-doutor da Universidade de \\ Tulane, EUA, pesquisador CNPq, Conselheiro \\ titular do Conselho de Cultura do Estado \\ do Rio de Janeiro, compositor letrista, \\ ensaista, contista, dramaturgo. Autor de 12 \\ livros e colaborador de revistas culturais \\ especializadas. Tem mais de 60 canções \\ gravadas por renomados intérpretes da MPB.
}

[resumo] No presente artigo busca-se colocar em foco a recorrência com que a moda é mencionada nos versos da música popular brasileira, revelando hábitos e costumes da sociedade em diferentes momentos da nossa história , servindo como documento de época.

moda; música popular brasileira; estudos culturais.

[abstract] The aim in the present article is to focalize how frequent fashion world is present in Brazilian popular music words (rhymes) and how this presence reveals social customs and habits in different moments of our history as a sort of period document.

[key words] fashion; brazilian popular music; cultural studies. 
A música popular brasileira tem um lugar de grande relevância na formação cultural da nossa gente. Fomos educados fazendo um percurso singular, aos saltos, ultrapassando etapas fundamentais. Analfabetos, iletrados e, portanto, sem tradição livresca, acabamos "alfabetizados" pelo rádio que, nos anos 1930 do século XX, era já o mais popular meio de comunicação, ainda que recém-inaugurado na década anterior (1922). 0 fato é que somos uma gente que aprendeu de ouvido, o que sabe é de ouvido e que, com o advento da televisão, nos idos de 1960, transmutou-se de ouvinte em telespectador. Fica evidente, por conseguinte, que a relação da grande parte da população com a poesia se dá por meio da canção popular e não do texto poético literário. Nosso calendário afetivo é costurado por uma trilha sonora que revela de forma transparente as singularidades de cada um de nós.

Se é verdade que um segmento da canção faz as vezes da crônica como é recorrente na marchinha carnavalesca, quando passa em revista os fatos mais representativos do ano que antecede 0 carnaval, podemos, então, afirmar que é possivel ler, nos versos do cancioneiro, aspectos comportamentais diversos que caracterizam momentos históricos distintos e, conseqüentemente, hábitos cotidianos, entre eles a moda.

No carnaval de 1925, fez grande sucesso a marchinha de autoria de Pedro de Sá Pereira e Américo F. Guimarães intitulada Tudo à la garçonne, que atesta o quanto o corte do cabelo feminino à altura da nuca ganhou ares de escândalo naquele momento. Antes da transcrição dos versos, vale reproduzir o que nos informa Edigar de Alencar no livro O Carnaval carioca através da música.

0 aparecimento escandaloso do romance La garçonne (1922), de Vitor Margueritte, que logo esgotou sucessivas edições na França e se espalhou por todo o mundo, repercutiu com intensidade no Brasil, no ano seguinte, quando foi lançada a edição brasileira sob o título $A$ Emancipada e como subtítulo o título original. Tudo era à la garçonne, inclusive o cabelo feminino aparado na altura da nuca - grande escândalo na época! (1979, p. 164)
Os versos da marchinha evidenciam que a "Paris tropical" idealizada por Pereira Passos (o Rio de Janeiro) não perdia tempo quando o assunto era moda:

Tudo à la garçonne (Pedro de Sá Pereira e Américo F. Guimarães)

Hoje no Rio o que está na moda E o que se usa com perfeição Qualquer menina de alta roda Faz um mocinho andar contra a mão

Cabelos curtos, bem aparados Lindos cangotes nos deixam ver Tão sedutores e tão perfumados Que aos gabirus fazem padecer

\section{À la garçonne \\ É a tal moda de sensação \\ À la garçonne \\ Lá na avenida é a toda mão}

A mulher moderna, independente, que buscava se livrar do controle e da dependência do pai e posteriormente do marido, era vista com reservas por um expressivo segmento da sociedade. A moda dos cabelos curtos na nuca significava, em alguns casos, sinal de rebeldia como se a adepta ao corte indicasse que ela também poderia igualar-se, usar o cabelo curto como os rapazes (garçons).

0 número de canções compostas por Noel Rosa que trazem traços nítidos da crônica é bastante representativo. Sempre atento à cena urbana, aos aspectos circunstanciais da vida cotidiana, o poeta da Vila Isabel não poderia desaperceber o valor significativo do código da indumentária, "a boa aparência", na sociedade. Não é por outra razão que dá dimensão poética à pergunta: "com que roupa eu vou?", no antológico samba Com que roupa? (1931). Assumindo a voz de um eu-lírico malandro, nos versos finais, afirma:

Já estou coberto de farrapo, eu vou acabar ficando nu/ Meu paletó virou estopa e eu nem sei mais com que roupa? Com que roupa eu vou pro samba que você me convidou? 
Vale ressaltar que a palavra samba, na canção, tem sua carga significativa redimensionada, não se limitando à designação do gênero musical, refere-se ao baile, à festa. Para freqüentar o "samba" era fundamental ir bem apresentado. Tarzan (0 filho do alfaiate) é outro samba de Noel emblemático com relação ao universo da moda. Aqui o poeta chama a atenção para os ternos com enchimento, enormes ombreiras que modelavam a siIhueta masculina, dando a impressão de que todos os homens eram espadaúdos atletas. Provavelmente, inspirado em sua própria complexão franzina, faz uso de sua verve satírica para assumir a voz de um indivíduo "fracote" que se faz passar por um verdadeiro "Tarzan" quando vestido com um determinado terno de casimira. A menção ao tecido e o subtítulo (o filho do alfaiate) são indicativos preciosos sobre a moda das décadas de t-à-porter, quando a vestimenta masculina era toda confeccionada à mão por alfaiates e camiseiros e os cortes de tecidos eram, preferencialmente, importados da Inglaterra, no caso das casimiras e dos tropicais. Transcrevo parte da letra:

\section{Tarzan (O filho do alfaiate)}

(Noel Rosa)

Quem foi que disse que eu era forte? Nunca pratiquei esporte, nem conheço futebol...

0 meu parceiro sempre foi o travesseiro E eu passo o ano inteiro sem ver um raio de sol

A minha força bruta reside Em um clássico cabide, já cansado de sofrer

Minha armadura é de casimira dura Que me dá musculatura, mas que pesa e faz doer Eu poso pros fotógrafos, e distribuo autógrafos A todas as pequenas lá da praia de manhã Um argentino disse, me vendo em Copacabana:

'No hay fuerza sobre-humana que detenga este Tarzan' De lutas não entendo abacate Pois o meu grande alfaiate não faz

roupa pra brigar

Sou incapaz de machucar uma formiga Não há homem que consiga nos meus músculos pegar

Cheguei até a ser contratado

Pra subir em um tablado, pra vencer um campeão

Mas a empresa, pra evitar assassinato Rasgou logo o meu contrato quando me viu sem roupão

Na segunda metade de 1930 (1937), o baiano Assis Valente lança com estrondoso sucesso o samba Camisa listada, gravado por Carmen Miranda, em que narra a aventura carnavalesca de um respeitável cidadão (tinha anel de doutor) que, nos dias de folia, decide "soltar a franga". Logo no primeiro verso nos é informado que ele veste uma camisa listada, ícone da indumentária do malandro.

0 que chama a atenção em Camisa listada, além da citação da famosa marchinha carnavalesca Mamãe eu quero, de autoria de Jararaca (1937), é a criatividade do folião na montagem de sua fantasia de "Antonieta" composta de uma saia de veludo feita de cortina e uma combinação, peça do vestuário íntimo feminino atualmente em completo desuso e que consistia em uma espécie de vestido leve de alças, na maioria das vezes de cetim, ornado de delicadas rendas, usada sobre a calcinha e o sutiã. Para completar a fantasia, um estandarte de cabo de vassoura.

Camisa listada (Assis Valente)

Vestiu uma camisa listada e saiu por aí

Em vez de tomar chá com torrada ele bebeu parati Levava um canivete no cinto e um pandeiro na mão E sorria quando o povo dizia: sossega leão, sossega leão

Tirou seu anel de doutor para não dar o que falar E saiu dizendo eu quero mamar Mamãe eu quero mamar, mamãe eu quero mamar

Levava um canivete no cinto e um pandeiro na mão E sorria quando o povo dizia: sossega leão, sossega leão Levou meu saco de água quente pra 
fazer chupeta

Rompeu minha cortina

de veludo pra fazer uma saia

Abriu o guarda-roupa e arrancou minha combinação

E até do cabo de vassoura ele fez um estandarte

Para o seu cordão

Agora que a batucada já vai começando eu não quero e não consinto 0 meu querido debochar de mim Porque ele pega as minhas coisas vai dar o que falar

Se fantasia de Antonieta e vai dançar na Bola Preta

Até o sol raiar

Da conhecida polêmica musical travada entre Noel Rosa e Wilson Batista, que teve início em 1933, há dois sambas (Lenço branco, de Wilson Batista, e a réplica de Noel Rosa, Rapaz folgado) cujo foco é dirigido para os acessórios que compunham o traje do malandro, além da camisa listada e do terno branco.

Em Lenço branco, Wilson Batista, valorizando a atitude, o jeito de ser do malandro, indica na primeira estrofe:

"Meu chapéu do lado/Tamanco arrastando/Lenço no pescoço/Navalha no bolso/Eu passo gingando/Provoco e desafio/Eu tenho orgulho/Em ser tão vadio".

Em Rapaz folgado, Noel replica Wilson aconselhando-0 a vestir-se como um homem digno ao afirmar:

Rapaz folgado (Noel Rosa)

Deixa de arrastar tamanco

Pois tamanco nunca foi sandália

E tira do pescoço o lenço branco

Compra sapato e gravata

Joga fora esta navalha que te atrapalha

Com chapéu do lado deste rata

Da polícia quero que escapes

Fazendo um samba-canção

Já te dei papel e lápis

Arranja um amor e um violão

Malandro é palavra derrotista

Que só serve pra tirar

Todo o valor do sambista

Proponho ao povo civilizado

Não te chamar de malandro

\section{E sim de rapaz folgado}

Noel, mais uma vez, dando provas da genialidade de seu sarcasmo, reduz 0 malandro de Wilson Batista a um "rapaz folgado", destituindo-o de todos os acessórios característicos dos malandros de então: tamancos, como calçado, o lenço branco no pescoço, o chapéu de lado, que considera um equívoco (uma rata).

Ainda que aqui o levantamento de repertório seja brevíssimo e tenha como intuito dar o pontapé inicial na relação entre moda e MPB, não se pode furtar à observação da recorrência com que a vestimenta masculina freqüenta os versos do cancioneiro. Não só o malandro nos dá indicações de época. Os versos da segunda estrofe de Mucuripe (Belchior e Fagner), gravada em 1972 por Elis Regina, descrevem a roupa da personagem de forma bastante fashion, senão vejamos:

Calça nova de riscado

Paletó de linho branco

Que até o mês passado

Lá no campo inda era flor

Sob o meu chapéu quebrado

0 sorriso ingênuo e franco

De um rapaz novo e encantado

Com vinte anos de amor

Quem também gravou essa canção foi Roberto Carlos e, possivelmente, por essa razão lembrei-me que ele também, em suas composições, dá indicativos da moda. Quem não lembra de pelo menos dois "detalhes", da canção Detalhes (1970), em que a voz lírica ao dirigir-se à amada observa sobre o fato de ser "cabeludo" e vestir um jeans "desbotado", indicativos que combinam com precisão com a personagem que dirige um carro potente que "ronca", como mostra o fragmento selecionado da letra:

Se um outro cabeludo

Aparecer na sua rua

E isto lhe trouxer

Saudades minhas

A culpa é sua...

0 ronco barulhento

Do seu carro 
A velha calça desbotada

Ou coisa assim

Imediatamente você vai

Lembrar de mim...

Observe-se que a indumentária do romântico apaixonado, cabeludo, vestindo o famoso jeans délavé, que freqüenta as canções do Rei terá seu visual complementado em outra letra: Amante à moda antiga (1980). Agora o apaixonado old fashion que manda flores à amada chama a atenção do ouvinte ao destacar: "apesar do velho tênis/ E da calça desbotada/ ainda chamo de querida/ A namorada". 0 figurino do cabeludo, além da calça, tem agora tênis veIhos, o que confere a ele um ar largadão (low profile) premeditado. É interessante perceber que o cabelo longo referido por Roberto Carlos tem uma carga semântica bastante diversa da "cabeleira do Zezé", da marchinha carnavalesca homônima de autoria de José Roberto Kelly e Roberto Faissal (1963) em que a masculinidade do protagonista é posta em dúvida só por causa do cabelo (Será que ele é/Será que ele é). 0 questionamento entrega, sem sutileza, o machismo homofóbico, de então, período que antecede ao boom da contracultura, ao desbunde, ao flower power, ao sex, drugs \& rock and roll.

0 jeans, que supostamente iguala a todos nós, chegou a ser identificado com o próprio conceito de liberdade, nos duros anos em que imperava a censura, no início da década de 1970. No rádio e na televisão o jingle das calças jeans U.S. Top propagava aos quatro ventos: "liberdade é uma calça velha azul e desbotada que você pode usar do jeito que quiser". Toque com o qual se identificava instantaneamente a rapaziada cabeça-feita da época.

Em 1979, Gilberto Gil traz a público uma canção intitulada Tradição, em que ele memora e reconstrói a cidade da Bahia de sua meninice a partir da lembrança de uma moça, que morava no bairro do Barbalho, que conhece na condução. 0 fragmento da letra que aqui interessa é o que diz respeito ao namorado da tal moça. 0 modo de ser, a sua postura de machão, o seu charme estão tanto no fato de subir e descer do bonde andando, quanto no modo de usar a camisa aberta e uma calça jeans comprada no contrabando. Diz o trecho selecionado:

\section{Tradição (Gilberto Gil)}

Conheci uma garota que era do Barbalho

Uma garota do barulho Namorava um rapaz que era muito inteligente Um rapaz muito diferente Inteligente no jeito de pongar no bonde E diferente pelo tipo De camisa aberta e certa calça americana Arranjada de contrabando

E sair do banco e, desbancando, despongar do bonde

Sempre rindo e sempre cantando

Sempre lindo e sempre, sempre, sempre, sempre, sempre

Sempre rindo e sempre cantando

Anos mais tarde, 1984, o mesmo Gilberto Gil lança uma canção, intitulada Índigo Blue, em que, ainda uma vez, seguindo a linha de identificação do jeans com a juventude, com a liberalidade do jovem, sugere um clima de intenso erotismo que rola literalmente "debaixo dos panos", ou, para ser mais literal, debaixo das blusas e blusões.

Índigo blue (Gilberto Gil)

Índigo blue, indigo blue

Indigo blusão

İndigo blue, índigo blue

Índigo blusão

Sob o blusão, sob a blusa

Nas encostas lisas

do monte do peito

Dedos alegres e afoitos

Se apressam em busca

do pico do peito

De onde os efeitos gozosos

Das ondas de prazer se propagarão

Por toda essa terra amiga

Desde a serra da barriga

As grutas do coração

Índigo blue, índigo blue Indigo blusão

Índigo blue, índigo blue

Índigo blusão 
Sob o blusão e a camisa

Os músculos másculos

dizem respeito

A quem por direito carrega

Essa Terra nos ombros com todo o respeito

E a deposita a cada dia

Num leito de nuvens

suspenso no céu

Tornando-se seu abrigo

Seu guardião, seu amigo

Seu amante fiel

Em 1939, o mineiro Ary Barroso compõe uma canção que ganha a dimensão de hino: Aquarela do Brasil. A composição é um exemplo eloqüente de um tipo de samba, em grande voga no período ditatorial de Getúlio Vargas, que, com o tempo, cai em desuso, o samba exaltação. Projetava-se internacionalmente o Brasil por sua exuberância tropical, seu exotismo latino, tendo Carmen Miranda como nossa embaixadora.

Aquarela do Brasil, com sua letra grandiloqüente, ressalta lá pelas tantas a graça, a ginga, o charme da mulher brasileira que arrasta pelo salão o seu vestido rendado. Dizem os versos:

Quero ver essa dona caminhando

Pelos salões arrastando

0 seu vestido rendado Brasil!

Pra mim, pra mim, Brasil! Brasil!

Há nos versos de Ary alguns indicativos interessantes. 0 primeiro, o fato de nomear a mulher como "dona", indice de classe socioeconômica superior, já que freqüenta salões e, mais que isso, arrasta o vestido rendado. Esse vestido que arrasta é longo, de baile e feito de material nobre, a renda.

Entre as décadas de 1930 e 1960, eram recorrentes os bailes em que se exigia traje a rigor; os homens usavam casacas, smokings e summer jacketse as mulheres vestido longo de gala, chamados, geralmente, de vestido de baile. Estes tinham saias largas e rodadas, além de decotes generosos. Eram freqüentes também os corpetes tomara-que-caia rebordados com pedrarias, canutilhos e paetês. A "dona" que atravessa os salões em Aquarela do Brasil é do mesmo segmento social da personagem que baila a valsa no sonho-canção de Lamartine Babo e Francisco Matoso, de 1941:
Eu sonhei que tu estavas tão linda. Em Aquarela do Brasil, ela atravessava o salão, agora é embalada, "silente", nos braços do amado que a conduz na valsa "dolente". 0 clima onírico criado por Lamartine nos permite vislumbrar a personagem em seu alvo vestido de baile que nos remete, de imediato, aos bailes de formatura, de debutantes e às festas de 15 anos, celebrações valorizadíssimas então. Dizem os versos:

Eu sonhei que tu estavas tão linda (Lamartine Babo e Francisco Matoso)

Eu sonhei que tu estavas tão linda Numa festa de raro esplendor Teu vestido de baile lembro ainda Era branco todo branco meu amor A orquestra tocou uma valsa dolente Tomei-te aos braços, fomos dançando ambos silentes E os pares que rodeavam entre nós Trocavam juras, diziam coisas à meia voz Violinos enchiam o ar de emoções E de desejos uma centena de corações Pra despertar teu ciúme Tentei flertar alguém Mas tu não flertastes ninguém Olhavas só para mim

Vitórias de amor cantei Mas foi tudo um sonho, acordei

Enquanto as moçoilas casadoiras desfilam seus vestidos de baile nos salões da canção popular, nos salões carnavalescos e na movuca dos blocos no fim dos anos 1940 (1949) a grande estrela é Chiquita Bacana (Alberto Ribeiro e João de Barro - o Braguinha). A letra homenageia Josephine Baker, bailarina e cantora norte-americana que se tornou a grande atração dos palcos parisienses nos loucos anos 1920, quando aparecia em cena sumariamente vestida com um saiote de bananas e que, anos mais tarde, andou por aqui, se apresentando no Cassino da Urca. Na marchinha carnavalesca, Chiquita Bacana representa a mulher emancipada, dona do seu nariz, que "só faz o que manda o seu coração". Chama também atenção o fato de ser a personagem adepta da corrente filosófica vanguardista da época, 
o existencialismo, como indicação de ser Chiquita uma pessoa atenta às novidades, aos modismos. Dizem os versos:

\section{Chiquita Bacana \\ (Alberto Ribeiro e Braguinha) \\ Chiquita Bacana lá da Martinica \\ Se veste com uma \\ casca de banana nanica}

Não usa vestido, oi! não usa calção Inverno pra ela é pleno verão

Existencialista com toda razão

Só faz o que manda o seu coração, ôi!

Em 1975, Caetano Veloso lança uma paráfrase da Chiquita Bacana, chamada de A filha da Chiquita Bacana que, atualizando a liberação da mãe, é membro do "Women Liberation Front".

Voltando às décadas de 1930 e 1940, não poderia deixar de mencionar a famosa composição de Dorival Caymmi 0 que é que a baiana tem? (1939) que pela precisa descrição do traje da baiana serviu de orientação para que Carmen Miranda o estilizasse, tornando-se, nos anos 1940, uma verdadeira referência fashion. Na música de Caymmi são enumerados todos os elementos e acessórios que compõem a roupa da baiana: brinco, pulseira e corrente de ouro, pano-da-costa, bata de renda, saia engomada, sandália enfeitada e um rosário de ouro com uma bolota assim. Pela primeira vez no nosso cancioneiro aparece a palavra balangandã.

\section{0 que é que a baiana tem? (Dorival Caymmi)}

0 que é que a baiana tem? Que é que a baiana tem? Tem torço de seda, tem! Tem brincos de ouro, tem! Corrente de ouro, tem! Tem pano-da-costa, tem! Tem bata rendada, tem! Pulseira de ouro, tem! Tem saia engomada, tem! Sandália enfeitada, tem! Tem graça como ninguém Como ela requebra bem!

Quando você se requebrar, caia por cima de mim Caia por cima de mim Caia por cima de mim 0 que é que a baiana tem? Que é que a baiana tem? Tem torço de seda, tem! Tem brincos de ouro, tem! Corrente de ouro, tem Tem pano-da-costa, tem! Tem bata rendada, tem! Pulseira de ouro, tem! Tem saia engomada, tem! Sandália enfeitada, tem! Só vai no Bonfim quem tem 0 que é que a baiana tem? Só vai no Bonfim quem tem Um rosário de ouro, uma bolota assim Quem não tem balangandãs não vai no Bonfim Um rosário de ouro, uma bolota assim

Quem não tem balangandãs não vai no Bonfim

Oi, não vai no Bonfim Oi, não vai no Bonfim Um rosário de ouro, uma bolota assim

Quem não tem balangandãs não vai no Bonfim Oi, não vai no Bonfim Oi, não vai no Bonfim

É também Caymmi quem, anos mais tarde, compõe um samba cuja descrição da indumentária da personagem é propositadamente indicada como alguma coisa de estranha aos padrões do bom gosto. Tem como marca chamar a atenção para um tipo de acessório muito em voga na época (1940 e 1950), o bolero. 0 samba se inscreve na série de composições de Caymmi conhecida como sambas urbanos, uma vez que, diferente da maioria das músicas de sua lavra, a temática não focaliza a vida caiçara, praiana, nem o universo baiano. $\mathrm{Na}$ série urbana, $\mathrm{o}$ autor centra a atenção na cidade e seus personagens. Em Um vestido de bolero, é precisamente a moda, o vestido, que ocupa a berlinda. É bem verdade que a combinação proposta parece um tanto esdrúxula, um casaco/bolero bordô, podendo variar 0 tom para o vermelho com saia verde, azul ou branca de veludo. Mas isso se dá com o intuito de valorizar os atributos físicos de quem veste a aberração, como conclui o compositor: "é que debaixo do bolero, lero/tem você yayá." 
Um vestido de bolero

(Dorival Caymmi)

Um casaco bordô

Um vestido de veludo

Pra você usar

Um vestido de bolero

Lero, lero, lero

Já mandei comprar

Se o casaco for vermelho

Todo mundo vai usar

Saia verde, azul e branco

Todo mundo vai usar

Apesar dessa mistura

Todo mundo vai gostar

É que debaixo do bolero

Lero, lero, lero

Tem você yayá

Talvez o par perfeito para essa yayá de casaco bordô seja o rapaz descrito nos versos de Príncipe Pretinho, provavelmente, composta no fim da década de 1930, intitulada Só pra chatear, em que o personagem monta um figurino "descompensado", que beira ao absurdo clownesco para chamar a atenção da amada. Era ainda no tempo em que a vestimenta masculina estava basicamente associada ao terno como referência padrão. Veja a letra:

\section{Só pra chatear (Príncipe Pretinho)}

Eu mandei fazer terno

Só pra chatear

Com a gola amarela

Só pra chatear

Mandei bordar na lapela

0 nome que não era dela

Só pra chatear

Comprei um par de sapato branco

Mais sei que ela só gosta de marrom

Só pra chatear, só pra chatear

Cada pé de sapato tem um tom

Comprei um bangalô pra chatear lá na favela

mais vou morar na Lapa perto dela Só pra chatear ...

Como mencionado anteriormente, seria possivel estender esta conversa por muitas páginas, comprovando que a moda está refletida no espelho da MPB. Melhor porém limitar aqui esta provocação que poderá se desdobrar em muitas e muitas outras canções. Agora é moda, de Rita Lee, pode ser um ponto de partida, como também o minúsculo e sensacional Biquíni de bolinha amarelinha, famosa versão de Herve Cordovil, em 1960, para "Itsy bitsy teenie yellow polka dot bikini". Vestido tubinho, de Zé Keti, pode abrir outra vereda. Fico por aqui ouvindo o som da voz da moda diante do espelho da MPB: Existe alguém mais top do que eu?

\section{REFERÊNCIAS}

ALBIN, Ricardo Cravo. Dicionário de música popular brasileira on-line. Disponivel em <www.diconariompb.com.br>. Acesso em 01 jul. 2008.

ALENCAR, Edigar. O carnaval carioca através da música. Rio de Janeiro: Francisco Alves, 1979

CANÇADO, Beth. Aquarela brasileira. Brasilia: Corte, 1995, $6^{\circ}$ vol.

CANDIDO, Antonio. Recortes. São Paulo: Companhia das Letras, 1993.

COUTINHO, Afrânio. Enciclopédia de Literatura Brasileira. São Paulo: Global. 2001. $2^{\circ}$ vol.

GÓES, Fred (Org.) Brasil, mostra a sua máscara. Rio de Janeiro: Lingua Geral, 2007.

SÁ, Jorge de. A Crônica. São Paulo: Ática, 1999. 